\title{
Central-peripheral temperature difference, blood pressure, and arginine vasopressin in preterm neonates undergoing volume expansion
}

\author{
Heather J Lambert, Peter H Baylis, Malcolm G Coulthard
}

\begin{abstract}
Aim-To examine the effect of intravascular volume expansion for the treatment of hypovolaemia in sick preterm neonates. Methods-An intravenous infusion of $20 \mathrm{ml}$ per $\mathrm{kg}$ of $4.5 \%$ albumin was given to 14 preterm neonates. The effects on systolic blood pressure, central peripheral temperature difference (c-pT), and plasma arginine vasopressin concentration ( $\mathrm{pAVP}$ ) were measured.

Results-Thirteen babies showed a rise in systolic blood pressure. The six babies with the highest initial values of pAVP and c-pT showed a fall in both of these after infusion. The babies with lower initial pAVP (below 4 pmol/1) showed either a rise (two) or no change (six) after albumin infusion. There was a significant correlation between c-pT and $\log$ pAVP before $\left(\mathrm{r}^{2}=0.61 ; \mathrm{p}<0.05\right)$ and after infusion $\left(r^{2}=0.45 ; p<0.05\right)$.

Conclusions-Plasma AVP concentration is related to c-pT in unwell preterm newborns. This study suggests that clinical assessment of hypovolaemia in preterm newborns is poor and could be improved by using c-pT.

(Arch Dis Child Fetal Neonatal Ed 1998;78:F43-F45)
\end{abstract}

Keywords: hypovolaemia; albumin; central peripheral temperature; plasma arginine vasopressin; systolic blood pressure

Measurement of central-peripheral temperature difference (c-pT) has been used clinically for many years as an indicator of hypovolaemic shock. Its use has been widely advocated in textbooks of intensive care, anaesthetics, and surgery as a non-invasive measure of peripheral perfusion, though there are few published data. C-pT has been reported to be useful in the care of critically ill children ${ }^{1}$ and adult postoperative patients. $^{2}$ The temperature of the big toe has been reported to correlate with other measures of cardiac output in adults requiring intensive care and it may also correctly predict patient outcome. ${ }^{3}$ However, other investigators have reported no correlation between c-p T and cardiac index or systemic vascular resistance in shocked patients. ${ }^{4}$

Numerous reports have discussed the role of naturally occurring vasoconstrictor agents, including arginine vasopressin (AVP), in shock. ${ }^{5}$ AVP is released in response to hypotension and hypovolaemia in animals ${ }^{67}$ and adults. ${ }^{8}$ Measurement of plasma AVP concentration (pAVP) was therefore chosen as a marker of blood volume and pressure.
Intravascular volume expanders are often given to ill babies in neonatal intensive care units as part of normal clinical practice to treat shock or clinical hypovolaemia, but the criteria for doing so and for monitoring response are poorly defined. We therefore performed a study to measure the systolic blood pressure, c-pT, and pAVP before and after the use of volume expansion in the clinical situation. Our intention was not to influence the clinicians in their decision to use volume expansion, but to evaluate its effects in clinical use.

\section{Methods}

The study was performed at a regional neonatal unit in Newcastle upon Tyne and was approved by the Newcastle Health Authority/ University Joint Ethics Committee. At the time of the study local indications for administering intravascular volume expansion on this unit were not formally defined, but included the presence of an abnormally low or falling blood pressure and/or poor peripheral perfusion, as indicated by poor capillary refilling and cool periphery on palpation. The babies were studied consecutively if the medical team had made a clinical decision to give a volume expander and the researcher (HJL) was available. The underlying precipitating event causing medical concern was usually not stated or known. Details of the 14 subjects are shown in table 1 . Because volume expansion was given in urgent circumstances and for clinical indications, parental consent was not sought, but parents were subsequently informed that an extra volume of blood (about $1 \mathrm{ml}$ ) had been taken for this study.

The babies were assessed and systolic blood pressure, c-pT, and pAVP measured immediately before and within 1 to 3 hours of being given the albumin infusion. Twenty $\mathrm{ml}$ per $\mathrm{kg}$ birthweight of $4.5 \%$ albumin was infused over

Table 1 Details of subjects

\begin{tabular}{llcc}
\hline Subject & $\begin{array}{l}\text { Gestational age } \\
\text { (weeks) }\end{array}$ & $\begin{array}{l}\text { Birthweight } \\
(g)\end{array}$ & $\begin{array}{l}\text { Age at time of } \\
\text { study }(h)\end{array}$ \\
\hline 1 & 23 & 660 & 3 \\
2 & 28 & 1103 & 10 \\
3 & 30 & 1395 & 12 \\
4 & 32 & 1798 & 3 \\
5 & 34 & 1720 & 44 \\
6 & 34 & 1780 & 24 \\
7 & 32 & 1984 & 26 \\
8 & 25 & 900 & 31 \\
9 & 27 & 513 & 11 \\
10 & 28 & 1093 & 21 \\
11 & 29 & 1015 & 33 \\
12 & 34 & 2325 & 22 \\
13 & 27 & 785 & 4 \\
14 & 26 & 561 & 4 \\
\hline
\end{tabular}



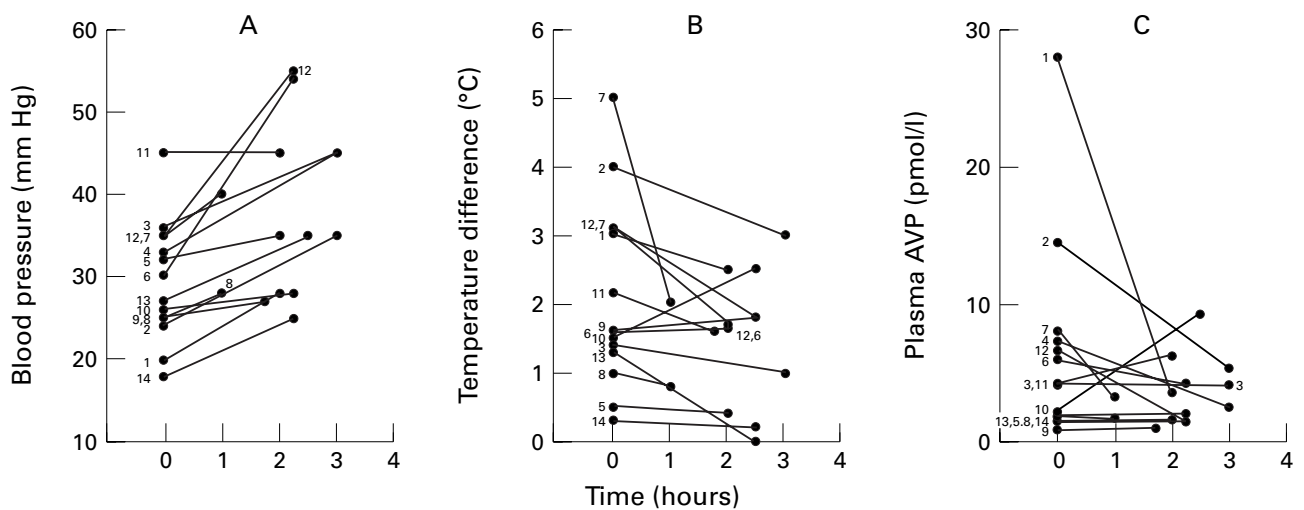

Figure 1 Changes in $(A)$ systolic blood pressure, $(B)$ central-peripheral temperature difference, and $(C) p A V P$ concentration after albumin infusion.

20 minutes in addition to normal maintenance fluids. Systolic blood pressure was measured with a hand held Doppler probe and a mercury or regularly calibrated aneroid sphygmomanometer. Central temperature was measured with an axillary thermometer. Peripheral temperature was measured with an electronic temperature probe taped to the dorsal or ventral aspect of the foot. The foot was always used in preference to the hand as preliminary investigations revealed that hand temperature values were sometimes higher than those recorded on the foot and the correlation between the temperature of the hands and feet was not consistent. If an intravenous infusion was sited in a foot or leg, that limb was not used for temperature monitoring. All babies were nursed in enclosed incubators with integral thermometers, and temperature was kept as constant as possible throughout the period of the study. None of the babies was receiving inotropes. Blood samples sufficient to give $500 \mu \mathrm{l}$ plasma were taken into cold lithium heparin tubes on ice, immediately cold centrifuged, and separated for later assay of AVP. Blood sampling was timed to coincide with a clinically required sample (such as blood gas or glucose measurement), unless taken from an indwelling arterial line. The same method of blood collection was used within each pair of samples. Plasma AVP concentration was assayed by using Florisil extraction and radioimmunoassay. ${ }^{9}$ The limit of detection of the AVP assay was $0.5 \mathrm{pmol} / \mathrm{l}$ with an interassay coefficient of variation of $11.5 \%$ at $2 \mathrm{pmol} / \mathrm{l}$. Plasma osmolality was measured by depression of freezing point (Camlab MOD200). The intermeasurement coefficient of variation was $0.5 \%$ at $300 \mathrm{mOsmol} / \mathrm{kg}$. Venous or arterial blood gas was measured on a Corning blood gas analyser for the clinicians' use. Parametric tests were used in the statistical analysis.

\section{Results}

Figure 1(A) shows the change in systolic blood pressure after albumin infusion (paired $t$ test; $\mathrm{p}<0.001)$. Thirteen of the 14 babies showed a rise in systolic blood pressure of between $8 \%$ and $80 \%$; one showed no change. There was no correlation between pAVP and systolic blood pressure either before or after infusion.
Figure 1(B) shows the changes in c-pT in ${ }^{\circ} \mathrm{C}$, and fig $1(\mathrm{C})$ shows the changes in pAVP before and after infusion. These reflected each other. The five babies with the highest initial pAVP had c-pT values of $3^{\circ} \mathrm{C}$ or greater, and showed a fall in c-pT after infusion. One baby who had a large increase in pAVP after infusion also showed a large increase in c-pT. The six babies with initial pAVP above $6 \mathrm{pmol} / 1$ showed a fall following albumin infusion, those with the highest initial values showing the greatest fall. The babies with initial pAVP below $4 \mathrm{pmol} / \mathrm{l}$ showed either a rise $(n=2)$ or no change $(n=$ 6) after albumin infusion.

There was a significant correlation between c-pT and log pAVP $\left(r^{2}=0.61, p<0.05\right)$ before infusion, and between c-pT and log pAVP $\left(r^{2}=0.45, p<0.05\right)$ after infusion (fig 2). No correlation was found between c-p T and systolic blood pressure.

The mean (SD) plasma osmolality was 285 (3.1) $\mathrm{mOsmol} / \mathrm{kg}$ before infusion and 285 (2.7) afterwards. The paired $t$ test showed no change in plasma osmolality before and after infusion of plasma (standard error of mean differences $=0.4 ; \mathrm{p}=0.7)$.

\section{Discussion}

Systolic blood pressure rose after albumin infusion in 13 out of 14 babies and was unchanged in one. The tendency for blood

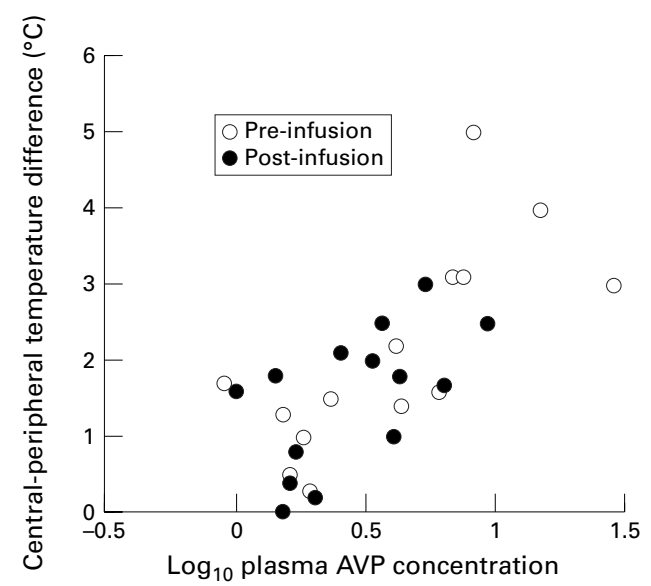

Figure 2 Correlation between central-peripheral temperature difference and $p A V P$ concentration before and after albumin infusion. 
pressure to rise in the postnatal period is well known, ${ }^{10}$ but it is unlikely that this change would be measurable over the short period (1 to 3 hours) of this study. Therefore, it seems most likely that the measured rise in systolic blood pressure observed was related to the infusion of albumin.

Following albumin infusion, a fall in pAVP was observed in six babies who also had a fall in $\mathrm{c}-\mathrm{pT}$; the babies with the highest initial pAVP having the highest initial c-pT and the greatest falls in both. Because administration of an intravascular volume expander was associated with a falling pAVP, it might be concluded that the high initial pAVP reflected hypovolaemia or hypotension. We did not test this by making other measurements related to volume statusfor example, central venous pressure.

AVP is known to be a potent vasoconstrictor and the c-pT observed might have merely been a reflection of peripheral vasoconstriction secondary to high concentrations of circulating AVP, and the high pAVP observed could have been caused by other stimuli. Plasma AVP concentration has been reported as high and to fall in the period immediately after birth, ${ }^{11-13}$ but the timing of this is variable and most studies are not based on serial measurements. Others have suggested no downward trend in sick newborns. ${ }^{14}{ }^{15}$ In our study all the babies were under 48 hours old and therefore changes in pAVP could have resulted from other changes occurring in the babies independent of the intervention of volume expansion. However, plasma osmolality did not alter and there were no other obvious events which would have been likely to have affected AVP release. None of the babies had a clinically suspected pneumothorax during the period of the study. As sequential head ultrasound examinations were not routinely performed in the unit at the time of the study, we cannot comment on intracranial bleeds as possible associated or precipitating events. The observation that both pAVP and c-pT fell within 3 hours of infusion of a volume expander strongly suggests that AVP was being released in response to hypovolaemia in those babies.

As changes in c-pT reflected changes in pAVP, we can infer that c-pT is a useful guide to hypovolaemia in these circumstances. The babies were all nursed in enclosed incubators and it may be that the constant ambient temperature was important. We cannot conclude that c-pT would necessarily be useful in other circumstances - for example, when radiant heaters are used.

Measurement of c-pT has been used clinically for many years. Its usefulness in adult patients has been disputed ${ }^{2-4}$ and as most shocked and critically ill adults have some form of invasive monitoring of volume status, its use could be regarded as outdated and irrelevant. The use of $c-p T$ in the management of shock is reported in children, in whom improvement in clinical signs corresponded with fluid replacement and a fall in temperature difference. ${ }^{1}$ Invasive monitoring of volume status is rarely performed in young children, and seldom in preterm neonates, because of practical difficulties and complications. Assessment of the use of non-invasive methods in these groups is therefore particularly important.

Albumin infusion was given on the clinical assessment of the medical team and we had no intention of influencing this decision. The fact that only six out of the 14 babies appeared, in retrospect, to have had evidence of hypovolaemia that was improved by volume expansion suggests that the indications for the use of volume expanders need to be examined. Because there is no real evidence that eight of the babies were hypovolaemic at the start of the study, we can conclude that the clinical diagnosis of hypovolaemia is poor. This study suggests that measurement of c-pT is more useful than systolic blood pressure in assessing hypovolaemia. Other forms of assessment, such as central venous pressure monitoring, need to be explored. Closer scrutiny of indications for use of volume expanders, together with better monitoring of response would also enable some babies to be left without intervention and some non-responders to be offered other treatment, such as inotropic support. ${ }^{16}$ When this study was planned there were clinical and ethical objections to performing a controlled trial of treatment $v s$ non-treatment. However, our finding of inappropriate and ineffective use of volume expanders supports the need for such studies.

We are grateful to Dr EN Hey for advice and comments, and to Dr J Hawdon and the medical and nursing staff of the Princess Mary Maternity Hospital for their assistance. HJL was supported by Medical Research Council project grant G87177585A. We thank Newcastle CHILD fund for additional financial support.

1 Aynsley-Green A, Pickering D. Use of central and peripheral temperature measurements in care of the critically ill child. Arch Dis Child 1974;49:447-81.

2 Ross BA, Brock, Aynsley-Green A. Observations on central and peripheral temperature in the understanding and management of shock. Br f Surg 1969;56:877-82.

3 Joly HR, Weil MH. Temperature of the great toe as an indication of the severity of shock. Circulation 1967;39:131-8.

cation of the severity of shock. Circulation 1967;39:131-8.
4 Woods I, Wilkins RG, Edwards JD, Martin PD, Faragher Woods I, Wilkins RG, Edwards JD, Martin PD, Faragher
EB. Danger of using core / peripheral temperature EB. Danger of using core / peripheral temperature
gradient as a guide to therapy in shock. Crit Care Med gradient as a g

5 Lefer AM, Hock CE. Vascular mediators in circulatory shock.In:Hardaway RM, ed. Shock: The reversible stage of dying. Massachusetts, USA: PSG Pub Co Inc, 1988:102-23.

6 Cowley AW, Switzer SJ, Guinn MM. Evidence and quantification of the vasopressin arterial pressure control system in the dog. Circ Res 1980;46:58-67.

7 Kasting NW. Simultaneous and independant release of vasopressin and oxytocin in the rat. Can $\mathcal{F}$ Physiol Pharmacol 1988;66:22-6.

8 Baylis PH. Posterior pituitary function in health and disease. Clin Endocrin Metab 1983;12:747-70.

9 Rooke P, Baylis PH. A new sensitive radioimmunoassay for plasma arginine vasopressin. F Immunoassay 1982;3:115-31.

10 Weindling AM. Blood pressure monitoring in the newborn. Arch Dis Child 1989;64:444-7.

11 Hoppenstein JM, Mittenberger FW, Moran WH. The increase in blood levels of vasopressin in infants during birth and surgical proceedures. Surg Gynaecol Obstet 1968;127:966-74.

12 Rees L, Forsling ML, Brook CGD. AVP concentrations in the neonatal period. Clin Endocrinol 1980;12:357-62.

13 Vanpee M, Herin P, Zetterstrom R, Aperia A. Postnatal development of renal function in very low birth-weight infants. Acta Paediatr Scand 1988;77:191-7.

14 Speer ME, Gorman WA, Kaplan SL, Rudolph AJ. Elevation of plasma concentrations of argenine vasopressin following perinatal asphyxia. Acta Paediatr Scand 1984;73:610-14.

15 McIntosh N, Smith A. Serial measurement of plasma AVP in newborn. Arch Dis Child 1985;60:1031-5.

16 Gill AB, Weindling AM. Randomised controlled trial of plasma protein fraction versus dopamine in hypotensive very low birhweight infants. Arch Dis Child 1993;69:284-7. 